\title{
Prognostic and Risk Factors Analysis of 106 Patients Undergoing Ventriculoperitoneal Shunt Combined with Cranioplasty
}

Hongbo Chang ( $\nabla$ changhongbo@163.com )

Department of Neurosurgery

\section{Ming Gao}

Pediatric department

\section{Wei-Dong Cao}

PLAGH: Chinese PLA General Hospital

Hu-Lin Zhao

PLAGH: Chinese PLA General Hospital

Gang Cheng

PLAGH: Chinese PLA General Hospital

\section{Sheng-Li Guo}

PLAGH: Chinese PLA General Hospital

\section{Peng Wang}

PLAGH: Chinese PLA General Hospital

\section{Jian-Ning Zhang}

PLAGH: Chinese PLA General Hospital

\section{Research}

Keywords: Ventriculoperitoneal shunt, Cranioplasty, Retrospective analysis, Prognosis, Risk factors

Posted Date: September 24th, 2020

DOI: https://doi.org/10.21203/rs.3.rs-78729/v1

License: (c) (i) This work is licensed under a Creative Commons Attribution 4.0 International License. Read Full License 


\section{Abstract}

Background: The study is to summarize the therapeutic effect and long-term prognosis of ventriculoperitoneal shunt combined with cranioplasty, analyze the operation-related risk factors and common complications, and summarize the experience, so as to improve the safety of the operation.

Methods: Retrospective analysis was performed on 106 patients diagnosed with post-operative skull loss with communicating hydrocephalus who underwent ventriculoperitoneal shunt combined with cranioplasty at our hospital. Age, gender, etiology, course of the disease, imaging manifestations, combined diseases, and prognosis of the patients were analyzed, as well as the risk factors and common complications of the operation.

Results: Among the 106 patients, 62 were males, and 44 were females, with an age range from 17 67 years old. There were 72 cases of craniocerebral injury, 23 cases of hypertensive intracerebral hemorrhage, and 11 cases of intracranial aneurysm rupture. There were 84 patients with a course of disease $\leq 3$ months during operation, and 22 patients with a course of disease $>3$ months. There were 71 cases with GCS score $\leq 8$, and 35 cases with GCS score $>8$. There were 10 patients with skull base fracture and cerebrospinal fluid (CSF) rhinorrhea and 24 patients with severe hydrocephalus. Among the 106 patients, 79 showed improvement after the operation, 24 showed no significant improvement, and 3 underwent the second operation due to aggravated condition. Most of the patients with poor prognosis were patients with GCS score $\leq 8$ points at the time of surgery, patients with previous skull base fracture and CSF rhinorrhea, patients with intraoperative hemorrhage $>800 \mathrm{ml}$, and patients with post-operative body temperature over $39^{\circ} \mathrm{C}$.

Conclusions: Our results revealed that ventriculoperitoneal shunt, combined with cranioplasty, is a useful approach. For patients with a high risk of operation, condition assessment, and monitoring should be strengthened. For patients with fever combined with infection or cerebral hemorrhage after the operation, active surgical treatment should be performed.

Trial registration: Not applicable

\section{Introduction}

Cerebral hernia caused by brain injury or cerebral hemorrhage is considered a neurosurgical emergency, which usually implies saving lives by decompression of bone plate under emergency treatment. The key to its timely treatment lies in surgical removal of etiology, removal of necrotic and hematoma tissue, and reduction of intracranial pressure and hemostasis. In clinical practice, traditional large bone flap decompression is often used in the treatment of patients with a cerebral hernia, resulting in post-operative skull defects. Some patients experience complications with communicating hydrocephalus for various reasons and further develop brain swelling and encephalocele, which increases the risk of secondary damage to brain tissue, leading to poor prognosis in most of the cases ${ }^{1,2,3}$. In patients with acute hydrocephalus, external ventricular puncture and drainage, lumbar cisterna drainage, or repeated lumbar 
puncture can be used to release CSF, thus achieving temporary relief in the early stage; however, the longterm application may lead to tube blockage, infection and bleeding, etc. $4,5,6$. Over recent years, with the improvement of diagnosis and treatment techniques and the improvement of shunt tube, the early simultaneous ventriculoperitoneal shunt combined with cranial repair has been commonly used as a surgical method for the treatment of skull loss and hydrocephalus. Nonetheless, there are still disputes about the timing, risks, and advantages of the simultaneous operation $7,8,9$.

This retrospective case study included 106 patients diagnosed with post-operative skull loss with communicating hydrocephalus and treated by ventriculoperitoneal shunt combined with cranioplasty at our hospital. Age, gender, etiology, course of the disease, imaging manifestations, combined diseases, and prognosis of the patients were respectively counted, and risk factors and common complications were analyzed.

\section{Materials And Methods}

\section{Materials}

A total of 106 patients (62 males and 44 females) who were clinically diagnosed with post-operative skull loss combined with communicating hydrocephalus and underwent ventriculoperitoneal shunt combined with cranioplasty at the Neurosurgery Department of the Sixth Medical Center of the General Hospital of the People's Liberation Army of China between January 2013 and December 2019 were included in the study. The average age of onset was $(40.2 \pm 15.3)$ years. Admission criteria were: all patients were confirmed by head CT and head MRI with communicating hydrocephalus and skull defects (diameter > $3 \mathrm{~cm}$ ). Symptoms of increased intracranial pressure, increased flap tension in the operative area, increased level of consciousness, or cognitive dysfunction was observed. Multiple post-operative head CT or head MRI reexaminations showed that the ventricle was gradually enlarged, and the value of the Interventricular diameter/interparietal diameter was $>0.26$. The written informed consent was obtained from all patients or their family members. Exclusion criteria were the following: patients with intracranial infections, coagulation disorders, and allergic constitution; patients with severe dysfunction of other organs such as heart, liver, and kidney; patients with previous ventriculoperitoneal shunt or other shunt failures and abdominal infections.

\section{Methods}

The clinical data of the patients were retrospectively analyzed, and the etiology, course of the disease, imaging manifestations, combined diseases, post-operative recovery, and prognosis were analyzed. The 106 patients were divided into three groups according to different pathogenic factors: craniocerebral trauma (trauma group), hypertension cerebral hemorrhage (hypertension group), and intracranial aneurysm rupture hemorrhage (aneurysm group). All patients underwent lumbar puncture within one week before surgery, measurement of pressure, and examination of CSF cell and biochemical were performed. 
Head CT and head MRI [T1-weighted, T2-weighted, fluid-attenuated inversion recovery (FLAIR), diffusionweighted imaging (DWI), and T1 enhanced sequence scanning] were performed in all 106 patients. Head CT examination, abdominal X-ray, or CT examination were performed in all patients within 1 month after the operation.

\section{Surgical steps}

After successful anesthesia, the patient was placed in a supine position with the head tilted to the healthy side. A ventriculoperitoneal shunt was performed first: adjustable pressure shunt tube of Medtronic with an initial pressure of $1.0 \sim 1.5 \mathrm{kPa}$ was selected. After positioning in the trigonometric area of the lateral ventricle, the $2 \mathrm{~cm}$ scalp was cut $2 \mathrm{~cm}$ away from the bone window edge of the skull defect. The shunt tube of the abdominal end was drawn along the tunnel of lateral neck, anterior chest and xiphoid process to the upper $1 / 3$ of the xiphoid process and navel, and the right rectus external edge $0.5 \mathrm{~cm}$ incision was made and $20 \sim 30 \mathrm{~cm}$ shunt tube was reserved for use. After drilling the skull, the dura mater was electrocuted. The shunt tube of the ventricular end was punctured into the lateral ventricle for $3 \sim 5 \mathrm{~cm}$, CSF was released, and the expanded brain tissue was retracted to the level of the bone window edge. The shunt valve was connected and secured. An incision of $1.5 \mathrm{~cm}$ was made at the lower edge of the navel, followed by laparoscopy into the abdominal cavity for observation. An abdominal puncture needle was used at the incision of $0.5 \mathrm{~cm}$ into the abdominal cavity, and a shunt tube was placed at the upper edge of the liver for $20 \sim 30 \mathrm{~cm}$. All incisions were sutured and bandaged. After the head area was disinfected again, skull repair was continued: scalp and subcutaneous tissue were cut through the original incision, skull defects were carefully separated and exposed, and the meninges were carefully protected. The precustomized 3D titanium mesh was used to cover and fix the skull defect, the dura was suspended, the subcutaneous drainage tube was placed, the incision was sutured, and the compression bandage was applied. Intraoperative antibiotics were used to prevent infection, and body temperature was monitored daily. The drainage tube was removed 1 to 2 days after the operation, and the suture line was removed 8 to 10 days after the operation.

\section{Efficacy evaluation and follow-up}

Preoperative evaluation and post-operative follow-up were carried out for all patients, and the efficacy was evaluated during the last follow-up in December 2019. Complete remission (CR) was defined as a substantial recovery of symptoms and signs and a significant improvement in the condition. No remission (NR) was defined as the aggravation of the post-operative condition, after which the second operation was performed. Partial remission (PR) was defined as the intervention between CR and NR, with no significant but stable improvement. The Glasgow Outcome Score (GOS) was used to calculate the prognosis: 5 points, complete or basic recovery with mild impairment; 4 points, slightly disabled, but can live independently, have a certain ability to work; 3 points: disabled but clearly aware, unable to live independently; 2 points, can open their eyes after waking up, plant survival; 1 point, death. The prognosis was good ( $4 \sim 5$ points), improved (3 points), ineffective ( 2 points), and dead (1 point). Total effective rate 
$=[($ good + improved $) /$ total number of cases $] \times 100 \%$. Meanwhile, the post-operative complications of the patients were observed and recorded. Preoperative and post-operative ( 6 months) observation indexes and criteria were compared ${ }^{10}$ : (1) Barthel method was used to evaluate the daily living ability of the patients before and after the operation. The total score was $0 \sim 100$ points. The higher the score was, the stronger the patient's daily living ability was. (2) The fugl-Meyer method was used to evaluate the limb motor function of patients before and after the operation. The total score was $0 \sim 100$ points. The higher the score, the better the limb motor function of patients. (3) GCS score was used to analyze the consciousness of the patients before and during the operation. GCS score from 13 to 15 was rated as excellent. GCS score from 9 to 12 was rated as good. A GCS score $\leq 8$ was considered poor. Excellent and good rate $=$ (excellent + good $) /$ total number of cases $\times 100 \%$.

\section{Statistical method}

SPSS 21.0 software was used for statistical analysis. A single sample Kolmogorov- Smirnov $Z$ test was used to test the data. The measurement data of normal distribution were expressed as $\dot{x} \pm s$, and the analysis of variance was used for the comparison between groups. The non-normal distribution measurement data were presented as $M\left(P_{25}, P_{75}\right)$, and the comparison between groups was performed by the Mann-Whitney non-parametric test. Enumeration data were expressed as a percentage, and the $\chi 2$ test was used for comparison between groups. $P<0.05$ was considered statistically significant.

\section{Results}

\section{History, etiology, and course of the disease}

Among the 106 patients, 72 had craniocerebral trauma, 23 had a hypertensive intracerebral hemorrhage, and 11 had intracranial aneurysm rupture hemorrhage. There were 27 cases of hypertension and 9 cases of diabetes. The time from the symptoms onset to the ventriculoperitoneal shunt combined cranial repair was $2.5 \sim 6$ months, with an average of $(4 \pm 1.5)$ months. There were 84 patients whose course of the disease was $\leq 3$ months at the time of operation and 22 patients whose course of the disease was $>3$ months. There were 51 patients with GCS score $\leq 8$, and 55 patients with GCS score $>8$. There were 10 patients with skull base fracture and CSF rhinorrhea and 24 patients with severe hydrocephalus. Among the 106 patients, 79 experienced improvement after the operation, 24 showed no significant improvement, while 3 had to undergo the second operation due to aggravated condition.

\section{CSF and imaging findings}

Lumbar puncture examination was performed within one week before surgery in all 106 patients; CSF pressure was increased $(120 \sim 300 \mathrm{mmH} 20)$, and protein was slightly increased (430 $780 \mathrm{mg} / \mathrm{L})$ in 11 patients. Imaging showed 41 cases of skull loss on the right side and 65 cases of skull loss on the left side. The imaging findings of all the patients showed a certain degree of encephalocele, interstitial edema, 
and encephalomalacia. The brain damage and surgical areas were well absorbed and recovered without intracranial infection and necrosis. Within 1 month after surgery, an abdominal X-ray or CT examination showed appropriate post-operative shunt pipe and a titanium plate in implant position. Case 1 is a patient with a ruptured intracranial aneurysm and cerebral hernia who underwent cranioplasty combined with the ventriculoperitoneal shunt (Fig. 1).

\section{Case 1}

Female, 54 years old patient presented on March 4, 2017 with a sudden headache, after which she gradually fell into a coma. Intracranial aneurysm rupture hemorrhage and cerebral hernia were diagnosed, and intracranial aneurysm embolization + craniotomy hematoma removal and bone flap decompression were performed emergently. The post-operative condition gradually stabilized. On June 19, 2017, head CT showed hydrocephalus, and lumbar puncture showed CSF pressure of $170 \mathrm{mmH}_{2} \mathrm{O}$. The patient received a GCS score of 6 points (E4V1M1), Barthel score of 9 points, Fugl-Meyer score of 7 points, and plant survival. On June 25,2017 , ventriculoperitoneal shunt + cranial repair were performed, resulting in satisfactory post-operative recovery, and post-operative GOS score of 2 points. A: Preoperative 3D printing was used to customize the skull of the patients with titanium plates, showing a large area of skull defects; B: Intraoperative placement of the shunt tube at the right occipital and fixation of the titanium plate; C: Position of intraperitoneal puncture needle under intraoperative laparoscopic observation and the situation when the head of the shunt tube entered the abdominal cavity; D: Preoperative HEAD CT findings (2017-619): right frontotemporal parietal skull defect, hydrocephalus, right temporal subdural effusion; $E$ : Half an hour after the operation, head CT indicated (2017-6-25): a small amount of intracranial gas under the titanium plate, and the shunt tube was in a good position. F: Head CT on the second day after the operation (2017-6-27): Tight titanium plate repair, intracranial gas absorption, ventricle shrinkage.

\section{Treatment and prognosis}

Among 106 patients, 79 were with post-operative remission (CR), 24 patients (1 patient complicated with a small amount of hematoma in the operative area that improved following self-absorption) with partial remission (PR), and 3 patients ( 2 patients had an epidural hematoma in the operative area 3 days after the operation, and their condition stabilized after the second operation removed the hematoma; 1 patient had post-operative intracranial gas accumulation and intracranial infection, and his condition stabilized after secondary surgery successfully repaired the anterior cranial fossae leakage and anti-infection treatment) with no remission (NR) (see Case 2 and Fig. 2). Craniocerebral trauma group (72 cases), hypertension cerebral hemorrhage group (23 cases), intracranial aneurysm rupture hemorrhage group (11 cases) that were compared for the maximum diameter of skull defect $(P>0.05)$ and post-operative GOS score $(P>$ 0.05 ) showed no obvious differences between the surgical effect of different etiologies and skull defect size (Table 1). Among 106 patients, the GOS score was good in 79 cases, improved in 18 cases, ineffective in 9 cases, poor in 0 cases, and the total effective rate was 91.51\% (97/106). The Barthel score, Fugl-Meyer score, and GCS score were preoperatively and postoperatively (6 months) compared in patients, revealing 
significantly improved operation effect $(P<0.05)$ (Table 1$)$. Postoperative complications occurred in 7 patients, including 2 cases of subcutaneous hydrops, 1 case of cerebrospinal rhinorrhea complicated with intracranial infection, 1 case of a cerebral hemorrhage, and 2 cases of an epidural hematoma.

\section{Case 2}

Male, 52 years old patient was hit on the head by an unknown object on August 17, 2015. He was diagnosed with bilateral frontal lobe contusion, subdural hemorrhage, and subarachnoid hemorrhage. Emergency craniotomy for hematoma removal and bone flap decompression was performed. On November 23, 2015, head MRI indicated hydrocephalus, CSF pressure of $140 \mathrm{mmH}_{2} \mathrm{O}$, deepened consciousness, and multiple seizures. The patient received a GCS score of 6 points (E3V1M2), a Barthel score of 10 points, and a Fugl-Meyer score of 7 points. On December 22, 2015, ventriculoperitoneal shunt + cranial repair was performed, and post-operative recovery was satisfactory. On January 17, 2016, the patient developed epileptic seizures and CSF rhinorrhea again, with a fever of $39^{\circ} \mathrm{C}$. On February 7,2016 , the craniotomy was performed again to find the cranial base and dural fistula, which were repaired tightly. After the operation, meropenem combined with vancomycin for anti-infection treatment was given, and the patient's condition gradually recovered. The GOS score was 2 points after the operation. A: Head CT findings (October 29, 2015): cerebral contusion and cerebral softening lesion formation in the bilateral frontal lobe, right frontal skull defect, left temporal subdural effusion. B: Three-dimensional reconstruction CT findings of the head (December 14, 2015): large skull defect on the right forehead, frontal sinus opening, post-operative changes of the left frontal skull. C: Head MRI suggested (November 23, 2015): the formation of a softening lesion of bilateral frontal lobe contusion, right frontal skull defect, hydrocephalus, and reduced left temporal subdural effusion. D: Head CT suggested intracranial gas accumulation after surgery (2016-1-17). E: During the second operation (2016-2-7), the fracture of frontal sinus was poorly healed and open, with a large artificial dural fistula. F: After anti-infection treatment, head CT revealed (May 15, 2016) that strict skull repair, intracranial gas absorption, and good healing.

Table 1

Classification, skull defect size and GOS score of 106 patients, comparison results of Barthel score, FuglMeyer score and GCS score between preoperative and 6 months of postoperative $(\dot{\mathrm{x}} \pm \mathrm{s})$.

\begin{tabular}{|c|c|c|c|c|c|c|c|c|c|}
\hline Group & $n$ & $\begin{array}{l}\text { Skull } \\
\text { defect } \\
\text { diameter }\end{array}$ & $\begin{array}{l}\text { Preop } \\
\text { Barthel } \\
\text { score }\end{array}$ & $\begin{array}{l}\text { Postop } \\
\text { Barthel } \\
\text { score }\end{array}$ & $\begin{array}{l}\text { Preop } \\
\text { Fugl- } \\
\text { Meyer } \\
\text { score }\end{array}$ & $\begin{array}{l}\text { Postop } \\
\text { Fugl- } \\
\text { Meyer } \\
\text { score }\end{array}$ & $\begin{array}{l}\text { Preop } \\
\text { GCS } \\
\text { score }\end{array}$ & $\begin{array}{l}\text { Postop } \\
\text { GCS } \\
\text { score }\end{array}$ & $\begin{array}{l}\text { Postop } \\
\text { GOS } \\
\text { score }\end{array}$ \\
\hline $\begin{array}{l}\text { Trauma } \\
\text { group }\end{array}$ & 72 & $\begin{array}{l}15.7 \pm \\
3.4\end{array}$ & $\begin{array}{l}31.4 \pm \\
11.0\end{array}$ & $\begin{array}{l}72.9 \pm \\
16.6^{\star}\end{array}$ & $\begin{array}{l}38.4 \\
\pm 10.9\end{array}$ & $\begin{array}{l}71.9 \pm \\
18.2^{\star}\end{array}$ & $\begin{array}{l}6.4 \pm \\
3.5\end{array}$ & $\begin{array}{l}13.7 \pm \\
1.0^{*}\end{array}$ & $\begin{array}{l}3.2 \pm \\
0.6\end{array}$ \\
\hline $\begin{array}{l}\text { Hypertension } \\
\text { group }\end{array}$ & 23 & $\begin{array}{l}15.1 \pm \\
3.0\end{array}$ & $\begin{array}{l}30.2 \pm \\
13.9\end{array}$ & $\begin{array}{l}74.0 \pm \\
15.5^{\star}\end{array}$ & $\begin{array}{l}39.7 \\
\pm 11.0\end{array}$ & $\begin{array}{l}79.4 \pm \\
16.5^{\star}\end{array}$ & $\begin{array}{l}6.0 \pm \\
3.1\end{array}$ & $\begin{array}{l}12.9 \pm \\
1.5^{\star}\end{array}$ & $\begin{array}{l}2.5 \pm \\
0.7\end{array}$ \\
\hline $\begin{array}{l}\text { Aneurysm } \\
\text { group }\end{array}$ & 11 & $\begin{array}{l}14.8 \pm \\
2.6\end{array}$ & $\begin{array}{l}29.7 \pm \\
12.8\end{array}$ & $\begin{array}{l}70.1 \pm \\
17.8^{\star}\end{array}$ & $\begin{array}{l}42.1 \\
\pm 13.3\end{array}$ & $\begin{array}{l}76.3 \pm \\
17.7^{\star}\end{array}$ & $\begin{array}{l}5.9 \pm \\
2.8\end{array}$ & $\begin{array}{l}13.4 \pm \\
1.8^{*}\end{array}$ & $\begin{array}{l}3.1 \pm \\
0.5\end{array}$ \\
\hline
\end{tabular}




\section{Univariate analysis of surgical risk factors in patients}

According to the final clinical recovery, the patients were divided into the group with good prognosis (CR patients, whose symptoms and signs recovered and condition significantly improved) and the group with poor prognosis (PR and NR patients, whose condition did not significantly improve or their condition worsened after the operation, and who had to undergo a second operation), and the risk factors of the operation were analyzed. The results showed that the poor prognosis group included patients with GCS score $\leq 8$ points at the time of operation, patients with previous skull base fracture and CSF rhinorrhea, patients with intraoperative hemorrhage $(>800 \mathrm{ml})$, and patients with body temperature over $39^{\circ} \mathrm{C} 3$ days after the operation (Table 2).

Table 2

Univariate analysis of surgical risk factors in patients.

\begin{tabular}{|llll|}
\hline Clinical project & $\begin{array}{l}\text { Group with good } \\
\text { prognosis(n= 79) }\end{array}$ & $\begin{array}{l}\text { Group with poor } \\
\text { prognosis(n= 27) }\end{array}$ & $\begin{array}{l}P \\
\text { Value }\end{array}$ \\
\hline Male[n(\%)] & $47(59.5)$ & $15(55.6)$ & 0.341 \\
\hline Age[M $\left(P_{25}, P_{75}\right)$,year] & $39(30,45)$ & $44(35,52)$ & 0.457 \\
\hline Months before operation $\left[\mathrm{M}\left(P_{25}, P_{75}\right)\right.$, month] & $3(2,4)$ & $5(4,6)$ & 0.124 \\
$\begin{array}{l}\text { GCS score of the operation time }\left[\mathrm{M}\left(P_{25}, P_{75}\right),\right. \\
\text { score] }\end{array}$ & $13(11,14)$ & $6(5,7)$ & $0.009^{*}$ \\
\hline $\begin{array}{l}\text { Patients with a history of skull base fracture } \\
\text { and cerebrospinal fluid rhinorrhea [n(\%)] }\end{array}$ & $2(2.5)$ & $8(29.6)$ & $<$ \\
$\begin{array}{l}\text { Patients with Intraoperative hemorrhage(> } \\
800 \text { ml) [n(\%)] }\end{array}$ & 0 & $5(18.5)$ & $0.001^{*}$ \\
\hline $\begin{array}{l}\text { patients with body temperature over 39 }{ }^{\circ} \mathrm{C} 3 \\
\text { days after operation [n(\%)] }\end{array}$ & 0 & $7(25.9)$ & $0.001^{*}$ \\
\hline $\begin{array}{l}\text { Note: * The comparison result between the group with good prognosis and the group with poor } \\
\text { prognosis was } P<0.05, \text { which was statistically significant. }\end{array}$ & $0.001^{*}$ \\
\hline
\end{tabular}

\section{Discussion}

The acute stage of craniocerebral trauma, hypertensive intracerebral hemorrhage, and intracranial aneurysm rupture hemorrhage often cause intracranial hypertension, cerebral hernia, and secondary injury of brain tissue. Some patients need emergency surgery, such as craniotomy, hematoma removal, or intracerebral aneurysm clipping. In order to timely remove the etiology and relieve the hernia and encephalocele, bone flap decompression is usually performed. Some of the patients may gradually develop communicating hydrocephalus after the operation, usually occurring three weeks to six months 
after the onset of the disease. At present, most scholars believe that severe cerebral contusion and cerebral hemorrhage are the basic causes of CSF circulatory dysfunction. A part of arachnoid granules gets destroyed while the bone flap is removed from a large area. The combined subarachnoid hemorrhage causes adhesions and necrotic brain tissue to block some arachnoid granules. The secretion of the choroid plexus and ependymal of ventricles is very exuberant due to the continuous stimulation of the blood component. Large skull defects make cranial volume in a variable state, resulting in brain tissue displacement, deformation, and abnormal enlargement of the ventricle. The flow direction of CSF changes affecting the normal production, circulation, and absorption of CSF and inducing or aggravating hydrocephalus. The patient's skull loses its protective effect, and the changes in the form and internal pressure of the ventricular system and hydrocephalus interact, leading to the aggravation of the patient's consciousness and neurological dysfunction ${ }^{4,5}$. Therefore, timely life support is essential in hydrocephalus complicated with skull defects.

In mild and moderate hydrocephalus, an early lumbar puncture may be used to release CSF to mitigate the damage. For severe hydrocephalus, external drainage of CSF by ventricular puncture or lumbar cisterna puncture is required. Yet, the long-term indwelling of external drainage tube may lead to excessive drainage, re-bleeding, tube blockage, and infection ${ }^{1}$. Generally, the drainage tube needs to be reset or replaced every 1 to 2 weeks. After controlling intracranial hypertension, cerebral edema, residual hemorrhage of CSF, and necrotic tissue in the acute stage, the ventriculoperitoneal shunt is the main choice for solving hydrocephalus at the early-stage with the determined etiology and relatively stable condition. Previous studies have shown that the majority of patients can reach a relatively stable period 2 $\sim 3$ months after the onset of the disease. At that time, the cerebral softening foci and the removal of bone flap area of the brain surface fibrous prosthesis form well, subcutaneous hydrops absorption is stable, and the flap shows no obvious atrophy. Considering that staging surgery often causes patients to miss the best convalescence treatment, which is not good for patients' consciousness and neurological function recovery, we adopted the method of early-stage (duration $\leq 3$ months at the time of operation) combined operation in most cases, obtaining the total effective rate of the final treatment of $91.51 \%$. In this study, there was no difference in the surgical results of patients with diseases due to craniocerebral trauma, hypertensive intracerebral hemorrhage, and intracranial aneurysm rupture hemorrhage, which may be due to well-controlled disease causes before the operation. There were still some patients whose course of disease lasted more than three months before surgery, and the proportion of patients' GCS score $\leq 8$ points was high, which may be related to the serious condition of patients admitted to our hospital. In this study, there were 2 patients with post-operative epidural hematoma, which caused aggravation. After hematoma was removed and re-covered with a titanium plate, the post-operative stability was restored in these patients. This suggests that this condition may be related to excessive drainage after shunt, tissue swelling caused by blood reflux disturbance of skin flap, muscle or brain surface fiber tissue after a repair, and incomplete hemostasis in the operative area. In this study, subcutaneous hydrops was found in 2 patients after surgery, which gradually improved after repeated syringe aspiration and appropriate compression bandage. Besides, one patient with CSF rhinorrheology complicated with intracranial gas and intracranial infection, whose anti-infection treatment effect was poor, was given a second craniotomy and 
debridement, and the frontal sinus and anterior skull base fractures with poor healing were completely closed with autologous fascia. Meanwhile, artificial dura was used to close the dura defect carefully, and the post-operative anti-infection treatment gradually restored stability. This highlights the importance of fully evaluating the preoperative recovery of the patients and performing three-dimensional head CT reconstruction and lung CT examination, lumbar puncture pressure test, CSF test and bacterial culture examination, enhanced MRI to exclude residual infection and necrotic lesions, and evaluating cerebrovascular and cerebral perfusion when necessary. It is also necessary to ensure that the patient's etiology has been removed, the skull base fracture fully healed, the bleeding and necrotic brain tissue absorbed and stable, and that patient can tolerate the operation well, thus reducing the risk of operation ${ }^{11}$. In this study, lumbar puncture examination was performed in all patients within one week before surgery, and increased intracranial pressure was detected. In addition, CSF red blood cell count, white blood cell count, sugar, chlorine and protein assay were conducted, and some patients showed a slight protein increase. We believe that lumbar puncture is not necessary for patients with the stable condition and no risk of meningitis. Nonetheless, for patients with the unstable condition, progressive hydrocephalus, affected consciousness, and suspected intracranial infection, lumbar puncture can be used to release CSF and relieve symptoms. At the same time, bacterial culture examination should be performed if necessary. In this study, all patients underwent laparoscopic observation, and the peritoneal shunt was placed at the upper edge of the liver, which reduced the blindness of placement and ensured that the peritoneal shunt was not mistakenly placed outside the peritoneum. The initial pressure in patients with shunt pump mainly referred to the preoperative results of lumbar puncture pressure within a week, which was between $1.0 \mathrm{Kpa}$ $\sim 1.5 \mathrm{Kpa}$, i.e., it was set to $1.5 \mathrm{Kpa}$ in 77 patients, and $1.2 \mathrm{Kpa}$ in 29 patients. On the $1 \mathrm{st}$ and $3 \mathrm{rd}$ day after the operation, the patients were reviewed with head CT to evaluate the changes of ventricular morphology and the size of the space between the dura mater and the titanium plate. Necessary adjustments were made to the pressure to prevent the risk of the excessive and insufficient shunt. It is possible that the shunt did not temporarily function due to the early release of part of CSF while the cranioplasty repair was occurring. With the increase of post-operative CSF secretion, the pressure of CSF rises, the anatomical morphology of ventricle and brain tissue recovers, and the shunt pump starts gradually. The gap between the titanium plate and the dura mater is gradually narrowed, and the air and bloody exudate in the gap are discharged through the drainage tube on the surface of the titanium plate. The drainage tube can be removed when the drainage fluid is gradually reduced to less than $20 \mathrm{ml}$.

In the present study, we evaluated the risk factors of combined surgery. Our results suggested that patients with poor consciousness and patients with severe brain tissue destruction after craniocerebral trauma or cerebral hemorrhage had a poor prognosis. This reminded us to strictly control the unnecessary flap hemorrhage during the operation, strengthen the preoperative and post-operative aseptic operation and infection prevention treatment, and strictly monitor the vital signs of patients after the operation. In particular, the change in body temperature was related to prognosis. Body temperature over $39^{\circ} \mathrm{C}$ indicated a high risk of infection, which is mostly related to the patients' intolerance to surgery and should be given sufficient attention. It is also essential to pay attention to whether the subcutaneous drainage tube is deviated and unobstructed and to observe the color and flow of drainage fluid. Some studies have suggested that ventriculoperitoneal shunt should be performed first, and cranial repair should be 
performed after hydrocephalus is relatively relieved, and the condition is stable ${ }^{12,13,14,15}$. In our opinion, staging surgery is more suitable for patients with severe hydrocephalus who have a long-term influence on the recovery of consciousness, and for patients with a short time of decompression of bone flap which is not good candidates for immediate repair or patients whose condition is not completely stable and may require additional craniotomy ${ }^{16,17}$.

Our results suggest that for successful combined operation, the following aspects should be considered: it is necessary to select the appropriate drainage tube, set the appropriate initial shunt pump pressure, identify appropriate location and depth of ventricular puncture and perform the operation in a fast and meticulous manner. Before repair, the ventricle should be punctured to release CSF and bring the swollen brain tissue back to the bone window level. It is necessary to shorten the operation time to reduce the exposure of shunt tube and brain tissue. Bleeding should be stopped as completely as possible. Threedimensional customized repair materials should be covered in situ and firmly fixed. The dural defect should be repaired. The incision of the flap should be closed by reducing tension. Effective evaluation of post-operative shunt position and shunt effect need to be performed. Necessary adjustment of treatment should be made according to the condition monitoring of post-operative patients.

By comparing the Barthel score, Fugl-Meyer score and GCS score of the patients before and after the operation, our results revealed that ventriculoperitoneal shunt combined with cranial repair had a significant effect on the treatment of post-operative skull defects complicated with hydrocephalus, thus suggesting it can effectively improve the patients' daily life ability and limb function, as well as timely improve the degree of coma, promote patients' prognosis and recovery, and help reduce the incidence of infection and complications of normal pressure hydrocephalus in patients. This approach has high application value and is beneficial to patients' early recovery.

\section{Conclusions}

Our results revealed that ventriculoperitoneal shunt, combined with cranioplasty, is a useful approach. For patients with a high risk of operation, condition assessment, and monitoring should be strengthened. For patients with fever combined with infection or cerebral hemorrhage after the operation, active surgical treatment should be performed.

\section{Declarations}

\section{Acknowledgements}

Not applicable.

\section{Funding}

The present study was supported by the Innovation and Development Foundation of the Sixth medical center of PLA general hospital. 
Authors' contributions

$\mathrm{HC}$ and $\mathrm{JZ}$ designed the research, $\mathrm{HC}, \mathrm{MG}, \mathrm{WC}, \mathrm{GC}, \mathrm{HZ}$ and SG performed follow-up of the research, $\mathrm{HC}$ and $\mathrm{PW}$ processed the data, $\mathrm{HC}$ wrote and edited the paper. All authors contributed to the intellectual content. All authors read and approved the final manuscript.

\section{Availability of data and materials}

The datasets used and/or analyzed during the current study are available from the corresponding author on reasonable request.

\section{Ethics approval and consent to participate}

Written informed consent was obtained from either the patient or a relative, and the present study was approved by the Ethics Committee of the Sixth Medical Center of PLA General Hospital.

\section{Consent for publication}

Written informed consent was obtained from either the patient or a relative.

\section{Competing interests}

The authors declare that they have no competing interests.

\section{References}

1. Rocque BG, Agee BS, Thompson EM, Piedra M, Baird LC, Selden NR, Greene S, Deibert CP, Hankinson TC, Lew SM, Iskandar BJ, Bragg TM, Frim D, Grant G, Gupta N, Auguste KI, Nikas DC, Vassilyadi M, Muh CR, Wetjen NM, Lam SK. Complications following pediatric cranioplasty after decompressive craniectomy: a multicenter retrospective study.J Neurosurg Pediatr. 2018,22(3):225-232.

2. De Bonis P, Pompucci A, Mangiola A, Rigante L, Anile C. Post-traumatic hydrocephalus after decompressive craniectomy: An underestimated risk factor. J Neurotrauma. 2010;27:1965-70.

3. Rahme R, Weil AG, Sabbagh M, Moumdjian R, Bouthillier A, Bojanowski MW, et al. Decompressive craniectomy is not an independent risk factor for communicating hydrocephalus in patients with increased intracranial pressure. Neurosurgery. 2010;67:675-8.

4. Honeybul S, Ho KM. Incidence and risk factors for post-traumatic hydrocephalus following decompressive craniectomy for intractable intracranial hypertension and evacuation of mass lesions. J Neurotrauma. 2012;29:1872-8.

5. Vedantam A, Yamal JM, Hwang H, Robertson CS, Gopinath SP. Factors associated with shuntdependent hydrocephalus after decompressive craniectomy for traumatic brain injury? J Neurosurg. 2017;16:1-6. doi: 10.3171/2017.1.JNS162721.

6. Manet R, Schmidt EA, Vassal F, Charier D, Gergelé L. CSF lumbar drainage: A Safe surgical option in refractory intracranial hypertension associated with acute posttraumatic external hydrocephalus. Acta 
Neurochir Suppl. 2016;122:55-9.

7. Meyer RM 4th, Morton RP, Abecassis IJ, Barber JK, Emerson SN, Nerva JD, Ko AL, Chowdhary MC, Levitt MR, Chesnut RM.Risk of Complications with Simultaneous Cranioplasty and Placement of Ventriculoperitoneal Shunt[J]. World Neurosurg. 2017,107:830-833.

8. Kutty RK, Sreemathyamma SB, Sivanandapanicker J, Asher P, Prabhakar RB, Peethambaran A, Libu GK.The Conundrum of Ventricular Dilatations Following Decompressive Craniectomy: Is Ventriculoperitoneal Shunt, The Only Panacea[J]? J Neurosci Rural Pract. 2018,9(2):232-239.

9. Jung YT, Lee SP, Cho JI. An improved one-stage operation of cranioplasty and ventriculoperitoneal shunt in patient with hydrocephalus and large cranial defect. Korean J Neurotrauma. 2015;11:93-9.

10. Fan MC, Li SF, Sun P, Bai GT, Wang N, Han C, Sun J, Li Y, Li HT.Early Intensive Rehabilitation for Patients with Traumatic Brain Injury: A Prospective Pilot Trial[J]. World Neurosurg. 2020,137:e183e188.

11. Zheng WJ, Li LM, Hu ZH, Liao W, Lin QC, Zhu YH, Lin SH.Complications in Staged Late Titanium Cranioplasty and Ventriculoperitoneal Shunting for Patients with Traumatic Brain Injury[J]. World Neurosurg. 2019,127:e1166-e1171.

12. Mustroph CM, Malcolm JG, Rindler RS, Chu JK, Grossberg JA, Pradilla G, Ahmad FU.Cranioplasty Infection and Resorption Are Associated with the Presence of a Ventriculoperitoneal Shunt: A Systematic Review and Meta-Analysis[J]. World Neurosurg. 2017,103:686-693.

13. Heo J, Park SQ, Cho SJ, Chang JC, Park HK.Evaluation of simultaneous cranioplasty and ventriculoperitoneal shunt procedures[J]. J Neurosurg. 2014,121(2):313-318.

14. Schuss P, Borger V, Güresir Á, Vatter H, Güresir E.Cranioplasty and Ventriculoperitoneal Shunt Placement after Decompressive Craniectomy: Staged Surgery Is Associated with Fewer Postoperative Complications[J]. World Neurosurg. 2015,84(4):1051-4.

15. Yang XF, Wang H, Wen L, Huang X, Li G, Gong JB. The safety of simultaneous cranioplasty and shunt implantation[J]. Brain Inj. 2017,31(12):1651-1655.

16. Linzey JR, Wilkinson DA, Nadel JL, Thompson BG, Pandey AS.Complications in Patients Undergoing Microsurgical Clipping of Intracranial Aneurysms with Pre-existing Ventriculoperitoneal Shunts Following a Cranial Procedure[J]. J Stroke Cerebrovasc Dis. 2019,28(3):845-849.

17. Tsang AC, Hui VK, Lui WM, Leung GK. Complications of post-craniectomy cranioplasty: Risk factor analysis and implications for treatment planning. J Clin Neurosci. 2015;22:834-7.

\section{Figures}



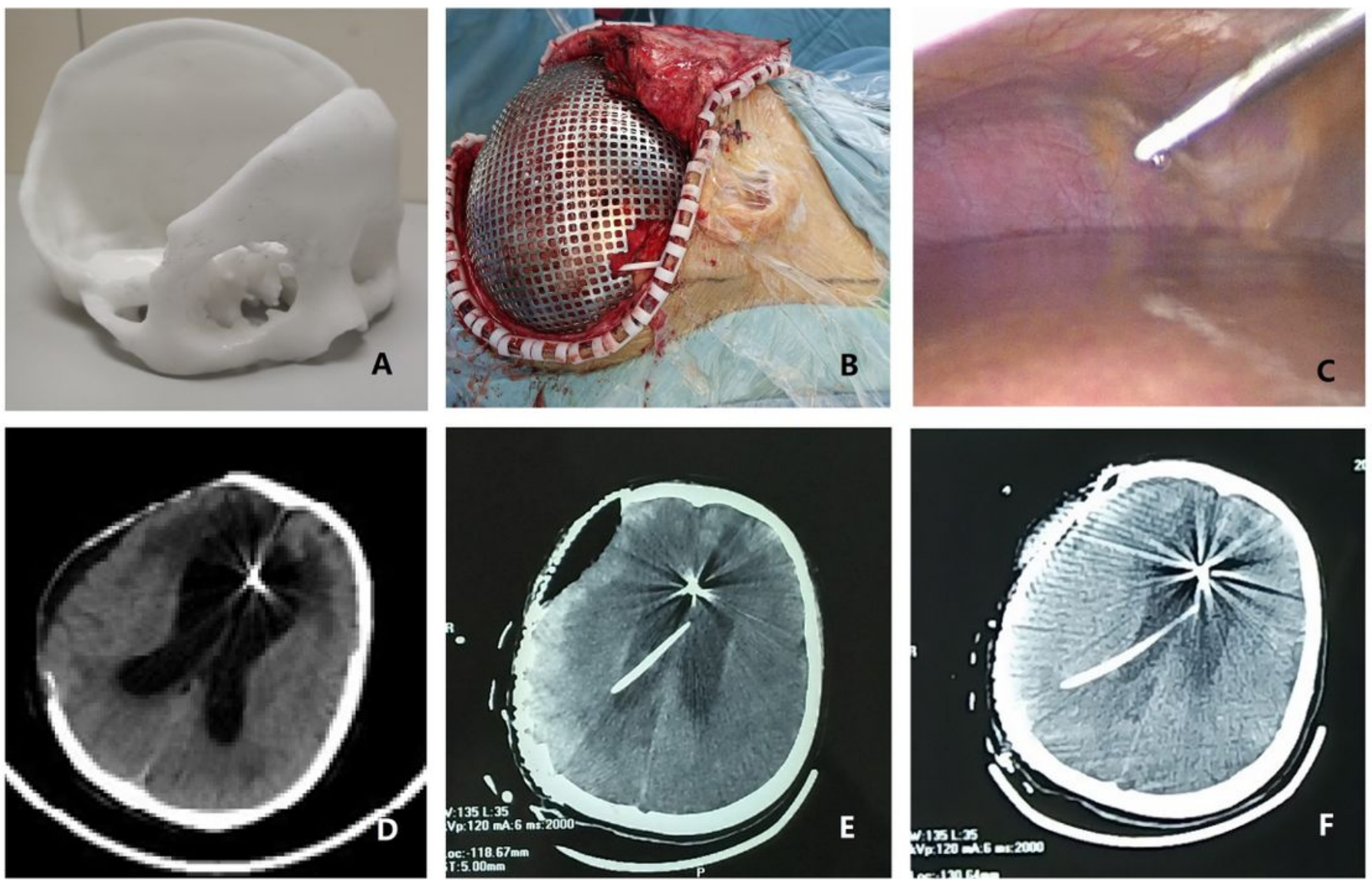

Figure 1

Imaging and operative status of 1 patient undergoing cranioplasty combined with ventriculoperitoneal shunt. 


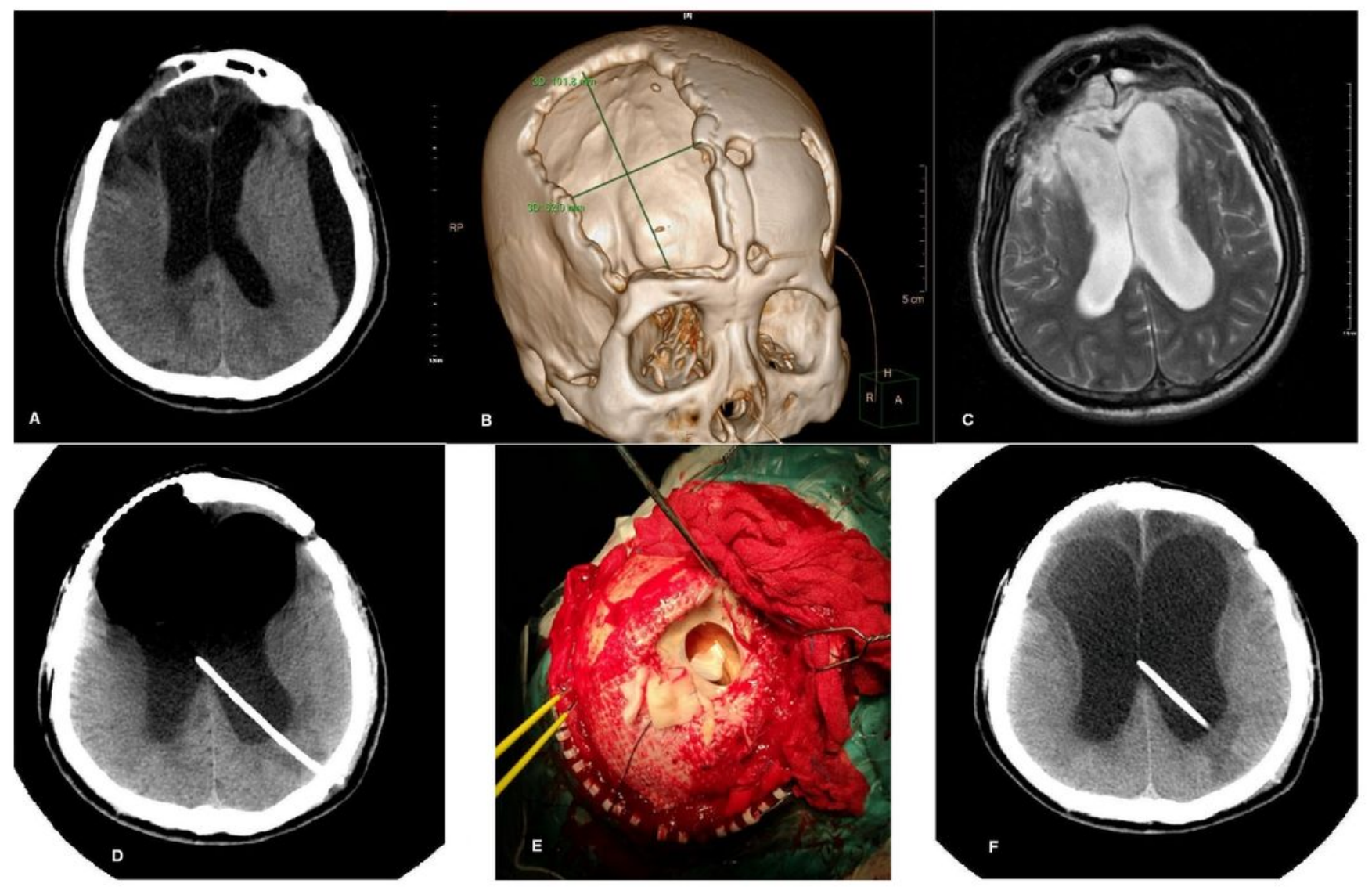

Figure 2

Imaging and intraoperative findings of 1 patient with postoperative CSF rhinorrhea combined with intracranial gas and intracranial infection. 